\title{
Early Intervention in Autism
}

\author{
Christina M. Corsello, PbD
}

\begin{abstract}
We now know that professionals can diagnose children with autism when they are as young as 2 years of age (Lord, 1995). Screening and the role of the pediatrician have become even more critical as we have recognized the stability of early diagnosis over time and the importance of early intervention. At this point, experts working with children with autism agree that early intervention is critical. There is professional consensus about certain crucial aspects of treatment (intensity, family involvement, focus on generalization) and empirical evidence for certain intervention strategies. However, there are many programs developed for children with autism that differ in philosophy and a lack of research comparing the various intervention programs. Most of the programs for children with autism that exist are designed for children of preschool age, and not all are widely known or available. While outcome data are published for some of these programs, empirical studies comparing intervention programs are lacking. In this review, existing intervention programs and empirical studies on these programs will be reviewed, with a particular emphasis on the birth to 3 age group. Key words: autism, early intervention, treatment
\end{abstract}

\section{BACKGROUND}

Autism is a developmental disorder that was first described by Leo Kanner in 1943, in a classic article that included case studies of 11 children. Since that time, the diagnostic criteria have evolved based on continued observations and research, resulting in the current criteria in the Diagnostic and Statistical Manual of Mental Disorders, Fourth Edition or DSM-IV (American Psychiatric Association, 1994) and the International Classification of Diseases or ICD-10 (World Health Organization, 1993). At the present time, autistic disorder is defined in terms of qualitative impairments in social interaction and communication, and restricted, repetitive, and stereotyped patterns of behaviors, interests, and activities, with impairments in one of these areas prior to the age of 3 years.

In addition to autistic disorder, there are 4 other specific diagnoses included within the autistic spectrum disorders (ASD) category, which is a term now preferred by most parents and professional organizations (Filipek

From the University of Michigan, Ann Arbor.

Corresponding author: Christina M. Corsello, PhD, University of Michigan, 1111 East Catberine St, 2nd Floor, Ann Arbor, MI 48109 (e-mail: um.autism@umich.edu). et al., 2000; Lord \& McGee, 2001). Included among them are 2 disorders that are defined by a regression in skills: Rett syndrome and childhood disintegrative disorder. These will not be the focus of this article. Recently, a specific gene has been linked with Rett syndrome (Cheadle et al, 2000). Childhood disintegrative disorder is a very rare disorder, with reported prevalence rates of 0.6 per 100,000 (Chakrabarti \& Fombonne, 2001). This disorder involves a period of normal development in the first 2 years of life, followed by a regression in a number of skill areas prior to the age of 4 years, resulting in autistic symptoms.

The other 2 ASD diagnoses are Asperger's disorder and pervasive developmental disorder - not otherwise specified (PDD-NOS). Asperger's disorder, like Autistic disorder, includes qualitative impairments in reciprocal social interactions, and restricted, repetitive, and stereotyped patterns of behaviors, interests, and activities. However, unlike Autistic disorder, it does not require qualitative impairments in communication. In addition, this diagnosis requires that there is no clinically significant language delay prior to 3 years of age, no cognitive delays, and that the criteria for another specific PDD have not been met. If children who have ever met criteria for autistic disorder are ruled out, the diagnosis 
of Asperger's disorder is very rare (Miller \& Ozonoff, 1997). Nevertheless, the diagnosis of Asperger's disorder is often used for milder cases of high-functioning autism. The final diagnosis within this general category is PDDNOS. This disorder is characterized by qualitative impairments in social interaction, accompanied by either qualitative impairments in communication or restricted, repetitive, and stereotyped patterns of behaviors, interests, and activities. There is still controversy about this diagnosis, including whether it is "almost autism" or "atypical autism" (Towbin, 1997).

Recent epidemiological studies have reported rates of ASDs as high as 66 per 10,000 (Fombonne, 2002), which is a surprising increase over rates reported in the past. Early identification has increased in importance, as many studies have found that children with ASDs who receive services prior to 48 months of age make greater improvements than those who enter programs after 48 months of age (Harris \& Weiss, 1998; Sheinkopf \& Siegel, 1998).

Over the past 10 to 15 years, there has been evidence that children with ASDs can be reliably diagnosed as young as 2 years of age (Lord, 1995). One of the largest errors in diagnoses of 2-year-olds referred for autism is underdiagnosing children on the basis of clinical impression when their scores on standardized measures are consistent with a diagnosis of autism (Lord \& Risi, 1998). Possible contributors to this bias are the variability in behaviors of 2-year-olds who have ASDs (Lord, 1995) and the lack of repetitive behaviors in autism that are often present in 3-year-olds, but may not be present in 2-year-olds with autism (Cox et al., 1999; Lord, 1995; Stone et al., 1999).

In this review, early intervention programs and empirical studies available on each of the programs (Table 1) will be reviewed, with a specific focus on the birth to 3 age group. When reviewing empirical support and programs, it is important to differentiate program outcome studies, which are designed to determine if a program is having the desired effect, from controlled empirical studies, which are designed to determine if the program or specific aspects of the program are clearly responsible for the changes observed.

When reviewing research on intervention for children with ASDs, there are several important considerations. These include the age groups included in the study, the control group, the control condition, and the outcome measures (Table 1). When reviewing programs, there are several components to cover, including method of intervention, the format, the setting, who implements the program, and whether it is child- or adult-directed (Table 2). Within this review, we will first focus on issues relevant to early intervention, followed by a review of programs and empirical support for programs, and suggested next steps with regard to intervention with very young children.

\section{INTERVENTIONS}

Over the years, there have been many treatments developed for children with autism, evolving from different philosophies. These include behavioral interventions, developmental interventions, and cognitivebehavioral interventions. While each program is based on a different philosophy and uses unique intervention strategies, there is also considerable overlap in components of the programs.

Two aspects of intervention that are common to most intervention programs designed for ASDs and have empirical support include the intensity of the program and the age at which children should begin intervention. Dawson and Osterling (1997), based on a review of programs for children with autism, report that most programs involve 15 to 25 hours of intervention a week. There is also empirical evidence that children who enter programs at younger ages make greater gains than those who enter programs at older ages (Harris \& Handleman, 2000; Sheinkopf \& Siegel, 1998). These studies generally compare children who are older than 4 or 5 years 


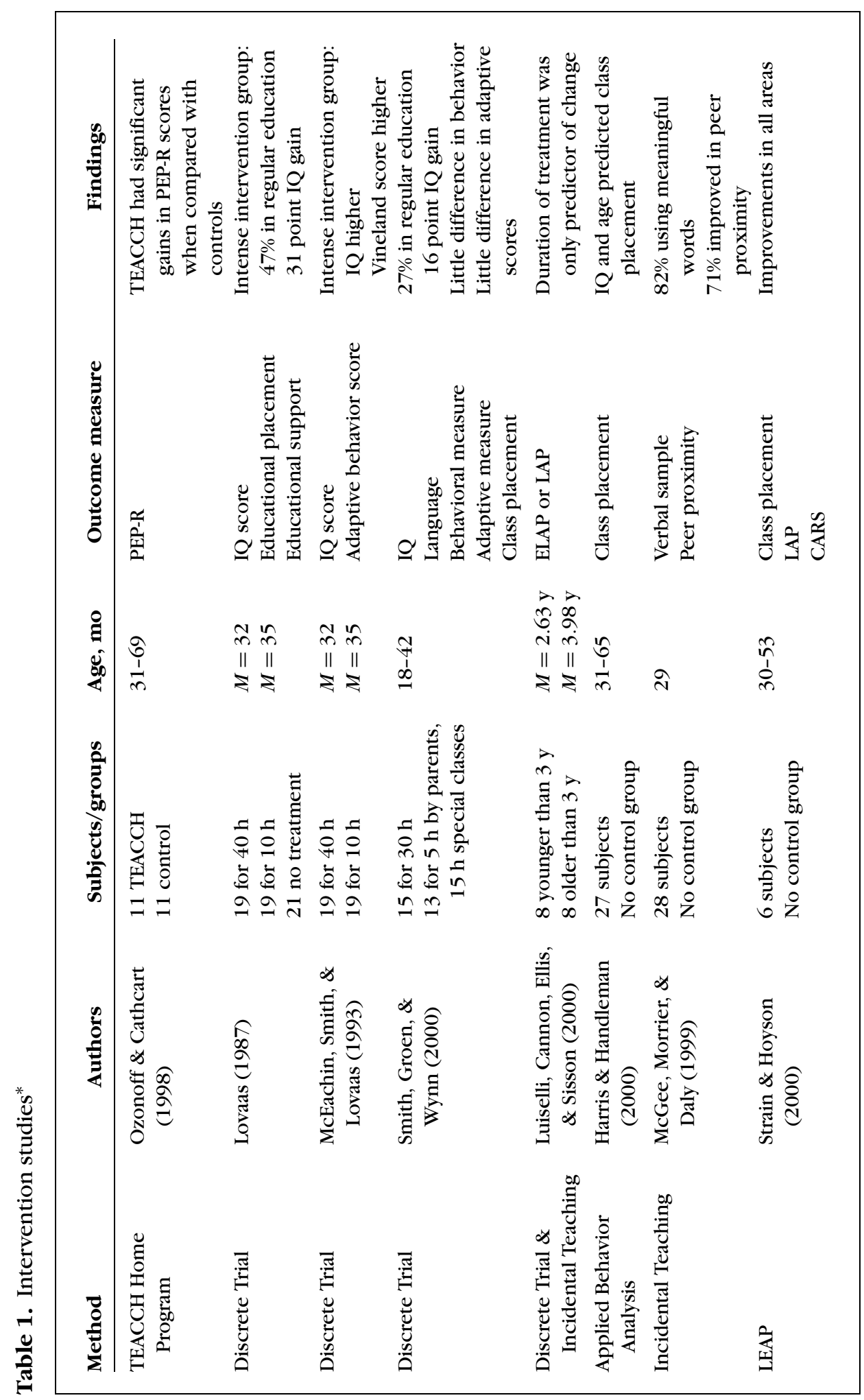

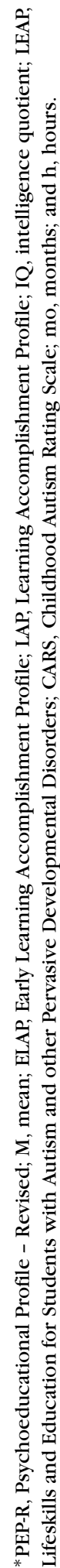


Table 2. Intervention programs

\begin{tabular}{|c|c|c|c|c|c|c|}
\hline Method & Authors/program & H/wk & Format & Setting & Implementer & $\begin{array}{l}\text { Adult- or } \\
\text { child-directed }\end{array}$ \\
\hline $\begin{array}{l}\text { Incidental } \\
\text { Teaching }\end{array}$ & $\begin{array}{l}\text { Walden Infant } \\
\text { Toddler Program }\end{array}$ & $30+$ & & $\begin{array}{l}\text { Child care } \\
\text { center }\end{array}$ & & Child \\
\hline & & & 1 to 1 & Home & Educational staff & \\
\hline $\begin{array}{l}\text { Social Pragmatic } \\
\text { Developmental } \\
\text { Approach }\end{array}$ & Wetherby \& Prizant & Variable & 1 to 1 & Home & $\begin{array}{l}\text { Parent } \\
\text { Therapist } \\
\text { Teacher }\end{array}$ & Child \\
\hline Structured Teaching & TEACCH & Variable & Group & $\begin{array}{l}\text { Classroom } \\
\text { Home }\end{array}$ & $\begin{array}{l}\text { Parents } \\
\text { School staff }\end{array}$ & Adult \\
\hline Discrete Trial & Lovaas (1987) & 40 & 1 to 1 & Home & $\begin{array}{l}\text { Student therapists } \\
\text { Trained consultants }\end{array}$ & Adult \\
\hline Discrete Trial & $\begin{array}{l}\text { Douglass } \\
\text { Developmental } \\
\text { Disabilities Center }\end{array}$ & $35-45$ & $\begin{array}{l}1 \text { to } 1 \\
\text { Small } \\
\text { group }\end{array}$ & $\begin{array}{l}\text { Class } \\
\text { Home }\end{array}$ & $\begin{array}{l}\text { School staff } \\
\text { Parents } \\
\text { Student therapists }\end{array}$ & Adult \\
\hline $\begin{array}{l}\text { Pivotal Response } \\
\text { Intervention }\end{array}$ & $\begin{array}{r}\text { Koegel, Koegel, \& } \\
\text { Harrows (1999) }\end{array}$ & Variable & $\begin{array}{l}1 \text { to } 1 \\
\text { Group }\end{array}$ & $\begin{array}{l}\text { Inclusive } \\
\text { setting } \\
\text { Home } \\
\text { Preschool }\end{array}$ & $\begin{array}{l}\text { Highly skilled specialists } \\
\text { Family } \\
\text { Consultants } \\
\text { School staff }\end{array}$ & Child \\
\hline $\begin{array}{l}\text { Behavioral and } \\
\text { Inclusion }\end{array}$ & LEAP* & 15 & Group & $\begin{array}{l}\text { Integrated } \\
\text { classroom }\end{array}$ & Teacher & Adult and child \\
\hline Developmental & Greenspan & Variable & 1 to 1 & Home & Parents, educational staff & Child \\
\hline Developmental & Denver Model & 22 & Group & Classroom & Trained staff & Child \\
\hline
\end{tabular}

*LEAP indicates Lifeskills and Education for Students with Autism and other Pervasive Developmental Disorders.

with those who are younger than 4 or 5 years. One study comparing children younger than 3 years with those older than 3 years did not find age differences in improvement (Luiselli, Cannon, Ellis, \& Sisson, 2000), which may suggest that 4 years of age is young enough to lead to significant gains. A potentially complicating factor is that children tend to make intelligence quotient (IQ) gains regardless of intervention at the younger ages (Gabriels, Hill, Pierce, \& Wehner, 2001; Lord \& Schopler, 1989). This also leads to difficulties in interpreting changes in IQ scores, which are often used as an outcome measure.

Most early intervention programs are designed for preschool-aged children, although they may include younger children in their programs as well. It is only more recently that we have been able to identify children with autism as young as 2 years of age. There are a few programs that are specifically designed for children between birth and 3 years of age. We will first cover the programs designed specifically for the birth to 3 age group, followed by widely available preschool programs, and finally preschool programs that are less widely available.

\section{EARLY INTERVENTION PROGRAMS DESIGNED FOR TODDLERS}

\section{Walden Toddler program}

The Walden Toddler Program (McGee, Morrier, \& Daly, 2001) is a program designed specifically for toddlers with autism. The program is based on a typical daycare model, with a focus on using incidental teaching and social inclusion. Incidental teaching is a method of applied behavior analysis (ABA) that uses behavioral principles within natural learning contexts. The environment includes toys and activities that are appealing to young children, and the adult expands on requests and activities that the child initiates. The program is very structured and works on individual goals within planned activities. The program includes typical toddlers and toddlers 
with autism, between the ages of 15 and 36 months. There are no controlled empirical studies of this program, but program evaluation data found that $82 \%$ of the toddlers used meaningful words when they left the program and $71 \%$ of the children showed improvements in their proximity to other children.

\section{Social pragmatic communication approach}

Amy Wetherby (Wetherby \& Prizant, 1999) has also developed strategies for teaching communication to young children with ASDs, based on a pragmatic communication developmental approach. She has not developed a comprehensive intervention program; however, she has focused her intervention strategies on social pragmatic communication development for children younger than 3 years. Within this approach, the importance of teaching in naturalistic contexts, using a facilitative rather than a directive style, providing opportunities for communication, and consistently and contingently reinforcing communication attempts are emphasized (Wetherby \& Prizant, 1999). Other strategies used in teaching communication to young children include incorporating environmental supports to create a predictable environment and teaching peers to initiate and respond to children with ASDs.

\section{COMPREHENSIVE PROGRAMS}

There are many comprehensive programs for children with ASDs, among the most widely known are the Developmental Intervention Model or Greenspan approach (Greenspan \& Wieder, 1997), the TEACCH Model (Marcus, Lansing, Andrews, \& Schopler, 1978; Mesibov, 1997; Schopler, Mesibov, \& Baker, 1982), the UCLA Young Autism Project (Lovaas, 1987), the LEAP (Lifeskills and Education for Students with Autism and other Pervasive Developmental Disorders) Program, and the Denver Model. Most of these programs have been developed for children of preschool age or older. The Walden Toddler Program is an exception, as it was designed specifically for toddlers. Most of the research on the available models is descriptive rather than based on empirical studies. Currently, there is no empirical evidence that one program is superior to another.

There are many common elements of these programs, although they differ considerably in philosophy. All of these programs include young children (mean ages between 30 and 47 months), active family involvement, and are intensive in hours (12-36 hours a week). In addition, in most of the model programs, staff is well trained and experienced in working with children with autism and the physical environment is supportive. It is important to note, however, that level of experience and training can vary considerably, particularly when adapting or incorporating model programs into the public domain. All of the programs focus on developmental skills and goals, and contain ongoing objective assessment of progress. The programs also use teaching strategies designed for the generalization and maintenance of skills, individualized intervention plans based on a child's strengths and needs, and planned transitions from preschool to school age. While there are many similarities, each program also has a different emphasis and defining features. Each of the programs will be reviewed below.

\section{The TEACCH program}

The TEACCH program is a statewide, community-based intervention program that emphasizes environmental organization and visual supports, individualization of goals, and the teaching of independence and developmental skills. The setting in which the program is implemented varies, depending on the abilities and needs of each child (selfcontained classroom, included classroom, home). Teaching strategies are designed to be meaningful to the child with autism, and are therefore taught within the natural environment and within context. The TEACCH program views ASDs as lifelong. From the beginning, it emphasizes skills that are important for future independence. One of the strengths 
of the TEACCH program is a focus on the lifespan and community-based intervention. One of the weaknesses is the lack of empirical studies of the program.

While the TEACCH program has been in existence for more than 30 years, there are relatively few empirical studies of the program. Two studies, comparing TEACCH interventions with only public education intervention, found significant differences in scores on the Psychoeducational Profile - Revised on follow-up testing (Ozonoff \& Cathcart, 1998; Panerai, Ferrante, \& Zingale, 2002). Only one of these studies focused on younger children (Ozonoff \& Cathcart, 1998) and compared a TEACCH home program, involving 10 sessions, in addition to services provided by the public school, to solely public school services for children between 2 and 6 years of age. Children in the TEACCH group had significantly higher scores on the PEP-R than the children in the control group following 4 months of intervention. The groups in this study were small, but were matched on age, PEP-R pretest scores, and severity of autism and not randomly assigned.

\section{Applied behavioral analysis programs}

One of the most widely known and soughtafter types of intervention is applied behavior analysis (ABA). Parents and professionals frequently associate the name Ivar Lovaas and the discrete trial format of instruction with ABA intervention. The popularity of the Lovaas intervention is partly the result of his 1987 study (Lovaas, 1987) and Catherine Maurice's (Maurice, 1993) book, both of which provide accounts of remarkable improvements and use the term "normal functioning" in the best outcome group of children with autism who received discrete trial intervention.

In reality, discrete trials and the Lovaas method is only one specific type of ABA intervention. Applied Behavior Analysis includes a number of other intervention strategies and programs that are based on behavioral principles. Many treatment studies are based on behavioral interventions, which is the case not only in autism but also in psychology in general.

The UCLA Young Autism Project uses the Lovaas method of intervention, specifically discrete trial intervention, implemented in a one-to-one setting by trained ABA therapists, supervised by trained professionals. The focus of the first year is on imitation, interaction, play, and response to basic requests. In the second year, the focus shifts to continued work on language, descriptions of emotions and preacademic skills. To teach generalization, the children practice the skills in other situations and with other people, once they have mastered them in a one-to-one setting.

The UCLA Young Autism Project has been empirically studied, and the most commonly cited article is Lovaas' article (Lovaas, 1987). At the time treatment began, the children had a mean age of 35 months in the experimental group and 41 months in the control group. The experimental group received one-to-one intervention 40 hours a week, and the control group received intervention 10 hours a week for 2 to 3 years. It was this article that started the belief that autistic children required intervention at least 40 hours a week. Lovaas (1987) used the term "normal functioning" in this article (p. 9), and he used IQ and class placement as outcome variables in this study. Understandably, parents have been quite influenced by this study. In a follow-up study of the children, between 9 and 19 years of age, the experimental group continued to have significantly higher IQs and Vineland scores than the control group (McEachin, Smith, \& Lovaas, 1993).

There have been numerous criticisms of this study, including nonrandom selection of groups (the age restriction was lower for children without language and children had to achieve a certain mental age to be included), nonrandom assignment to groups, and a large discrepancy between the number of hours of intervention between the control and experimental groups. However, it was one of the first empirical studies of an intervention program for children with autism. 
More recently, another study on the Lovaas method of intervention has been published and addresses some of the concerns of the original article (Smith, Groen, \& Wynn, 2000). In this study, the experimental group received approximately 25 hours a week of intervention while the control group received 5 hours a week of parent training. In the parent-training condition, the parents were asked to work with the children 5 hours a week at home, and they were enrolled in special education classrooms for 10 to 15 hours a week. The children with ASDs in this study had IQ scores between 35 and 75, and an age range of 18 to 42 months at the time of enrollment in the program.

As in the Lovaas study, the experimental group had higher IQs than the control group on follow-up. At the time of follow-up, between the ages of 7 and 8 years, $27 \%$ of the children in the experimental group were in regular education and had made a 16-point IQ gain. There were little differences in Child Behavior Checklist (CBCL) scores and Vineland scores between the 2 groups. The outcome was not as impressive as in Lovaas' original study, as only $27 \%$ of the children in this study were defined as best outcome (IQ $>85$ and in regular education without support) as opposed to $47 \%$ in the McEachin (McEachin et al., 1993) study. The average IQ gain was half that reported in the McEachin study, and the behavior and adaptive skills ratings were still reported as problematic in the experimental group in the Smith study. Clearly, children made gains in this program, but not the same degree of progress described in the original Lovaas and McEachin studies. The Smith study, with better controls and design, suggests that children improve more than they would with early education and focused parent support or education, but do not recover when they receive approximately 25 hours a week of intensive one-to-one ABA intervention.

Another model ABA program is the Douglass Developmental Center at Rutgers in New Jersey. This program has different levels, starting with a one-to-one format for the youngest children, then moving to a small classroom with a 2:1 ratio and then to a class with typical peers, using a model similar to the LEAP program, which is described later in this article. A follow-up study of the children in the program reported that age and IQ predicted outcome (Harris \& Handleman, 2000). Approximately $33 \%$ of the children had average IQs upon discharge from the program. It is important to note that $22 \%$ of the children (6 out of 27) had IQ changes from the range of mental retardation to average. Of these 6 children, 4 (67\%) were between 3 and 4 years of age and 2 (33\%) were between 4 and 5 years of age at the time they started the program. Upon exit from the program, 3 of these children were in special education, 2 were in integrated classrooms with support, and 1 child was fully included without support.

More recently, embedded trials, pivotal response training, and incidental teaching have emerged from the ABA literature. These techniques are less well known and less widely available at the present time, but hold some promise for intervention for very young children with autism. Contemporary ABA strategies include naturalistic teaching methods, such as natural language paradigms (Koegel, O'Dell, \& Koegel, 1987), incidental teaching (Hart, 1985; McGee, Krantz, \& McClannahan, 1985; McGee, Morrier, \& Daly, 1999), time delay and milieu intervention (Charlop, Schriebman, \& Thibodeau, 1985; Charlop \& Trasowech, 1991; Hwang \& Hughes, 2000; Kaiser, 1993; Kaiser, Yoder, \& Keetz, 1992), and pivotal response training or teaching core behaviors, with the idea that they will lead to changes in other behaviors and skills (Koegel, 1995; Koegel, Camarata, Koegel, Ben-Tall, \& Smith, 1998). These methodologies have commonalities, including teaching within natural contexts (during play, snack, work, within the classroom, at home), the use of natural reinforcers (reinforcing children for requesting by giving them what they are asking for), and systematic trials that are initiated by the child (the child makes the initial attempt).

Contemporary behavioral approaches have resulted in good outcomes for teaching language content, including single word 
vocabulary, describing objects and pictures, responding to questions, and increasing the intelligibility of speech (Goldstein, 1999; Koegel et al., 1998; Krantz, Zalewski, Hall, Fenski, \& McClannahan, 1981). McGee and colleagues (1999) also reported good outcomes through natural reinforcers of vocalization, speech shaping, and incidental teaching. Contemporary behavioral approaches have also been applied with some success to teach broader communication skills, such as functional communication, that may lead to decreases in challenging behaviors (Horner et al., 1990; Horner, Carr, Strain, Todd, \& Reed, 2000; Koegel, Koegel, \& Surratt, 1992). Spontaneous language is more difficult to teach and requires a number of naturalistic as well as developmental methods of instruction (Watson, Lord, Schaffer, \& Schopler, 1989). Children who use more spontaneous language earlier in treatment have more favorable language outcomes.

Very few intervention strategies have demonstrated success using behavioral interventions in teaching skills, such as joint attention and symbolic abilities, that focus on what are considered core deficits to children with autism. However, there are a few studies that documented some success in teaching symbolic play skills through pivotal response training (Stahmer, 1995; Thorp, Stahmer, \& Schreibman, 1995). Other studies that have demonstrated some improvements in these skills include increase in gaze to regulate social interactions, joint attention, shared positive affect, and the use of conventional gestures. Recently, there has also been documentation that naturalistic teaching of communication skills leads to improvements in joint attention in children with autism (Buffington, Krantz, McClannahan, \& Poulson, 1998; Hwang \& Hughes, 2000; Pierce \& Schreibman, 1995).

\section{The LEAP program}

There is an emphasis on including peers in intervention programs, because children with autism have difficulty generalizing skills learned with adults to interactions with peers (Bartak \& Rutter, 1973). Including typical peers is an essential component of both the LEAP program and the Walden Toddler program. The LEAP program includes 10 typical children and 6 children with autism between the ages of 3 and 5 years in each classroom. The children are in class for 15 hours a week. The classroom is structured and incorporates incidental teaching and other ABA methods of intervention. Interventions are both childand adult-directed. Peers are considered to be an essential element of the program (Harris \& Handleman, 1994). Peer-mediated techniques for increasing interactions involve teaching peers to be "play organizers." These strategies have been shown to be effective in increasing social interactions, which have generalized to some extent and been maintained over time (Goldstein, Kaczmarek, Pennington, \& Shafer, 1992; Hoyson, Jamieson, \& Strain, 1984; Strain, Kerr, \& Ragland, 1979; Strain, Shores, \& Timm, 1977).

\section{DEVELOPMENTAL INTERVENTIONS}

Developmental intervention is a specific term used to describe a philosophy and specific strategies for working with children with autism. One common feature of developmental interventions is that they are childdirected. In developmental interventions, the environment is organized to encourage or facilitate communicative and social interactions. The child initiates and the adult responds. There is limited empirical support for developmental approaches, but there is some support for language outcomes using such strategies (Hwang \& Hughes, 2000; Lewy \& Dawson, 1992; Rogers \& Lewis, 1989) and many case studies (Greenspan \& Wieder, 1997) using these approaches. Rogers and Lewis (1989) have documented improvements in symbolic play as a result of structured, development-based programs, and Lewy and Dawson (1992) also demonstrated improvements in gaze, turn taking, object use, and joint attention with a childdirected imitation strategy.

There are some limitations to developmental interventions. Because the intervention approach is child-directed, it requires that 
the child engage in behaviors to which the adult can respond. Many children with autism do not explore the environment in the way that typical children might. They may become stuck on certain activities or not play with the toys present in their environment. Developmental methods require considerable effort and skill on the part of the teacher or therapist, as she or he must know what child behaviors to respond as well as how to respond. When the child engages in behaviors that the therapist can respond to, and the therapist is skilled, it may be an effective intervention.

\section{The Greenspan model}

One of the most well-known developmental approaches is the Greenspan approach, also known as the Developmental Individual Difference (DIR) Model (Greenspan \& Wieder, 1997). The Greenspan model is described as a "relationship-based model," in which the goal is to help the child develop interpersonal connections that will lead to the mastery of cognitive and developmental skills, including (1) attention and focus, (2) engaging and relating, (3) nonverbal gesturing, (4) affect cuing, (5) complex problem solving, (6) symbolic communication, and (7) abstract and logical thinking. The program is based on following the child's lead and looking for opportunities to "close the circle of communication" or respond in a way that leads to expanding a skill or interaction. Within this model, it is recommended that a child spend at least 4 hours a day in spontaneous play interactions with an adult, at least 2 hours a day in semistructured skill building activities with an adult, and at least 1 hour a day in sensory-motor play activities. The Greenspan program is supplemented by time in an inclusive preschool program, speech and occupational therapy.

The DIR method of intervention is highly dependent on the skills of the parent or professional implementing the program. It requires that the adult recognizes when and how to respond to a child's actions and behaviors, which can make it difficult to imple- ment the program in the community. This differs from many behavioral approaches, which have a prescribed pattern of responses and adult-initiated teaching trials. There are currently no controlled studies of this program.

\section{The Denver model}

The Denver model (Rogers \& Lewis, 1989) is also based on a developmental model of intervention. This program is delivered within a classroom setting that is on a 12 -month calendar and meets 4 to 5 hours a day, 5 days a week. The focus is on positive affect, pragmatic communication, and interpersonal interactions within a structured and predictable environment. Almost all activities and therapies are conducted within a play situation. Goals of the program include using positive affect to increase a child's motivation and interest in an activity or person, using reactive language strategies to facilitate communication, and teaching mental representation.

There is outcome data available on the program, based on 31 children between 2 and 6 years of age with ASDs. Children demonstrated significant developmental improvements in cognition, language, social/ emotional development, perceptual/fine motor development, and gross motor development after 6 to 8 months in the program, after accounting for expected developmental progress. While only $53 \%$ of the children had functional speech when they entered the program, $73 \%$ had functional speech at follow-up.

\section{CONCLUSION}

The available evidence from a variety of programs and studies suggests that early intervention leads to better outcomes. As we have seen, a number of studies have demonstrated that children make greater gains when they enter a program at a younger age. It is important to keep in mind that most of the empirical support for the difference in gains is comparing children younger than 4 or 5 years to children older than 4-5 years of age. The preschool years are still considered "early" when it comes to early intervention. 
There are many strategies for working with children with autism and not all of them are equally known or available. Most of the empirical studies have been conducted on ABA interventions. While there is evidence that certain strategies can be effective for teaching specific skills to children with autism, there is not currently evidence that one program is better than any other. Furthermore, most of the programs are developed for children aged 3 and older, and many interventionists are currently attempting to adapt their programs to better meet the needs of the 0 to 3 age group. This leads to complications when recommending intervention programs to parents of young children with autism. At this time, there is a great deal of interest in the common elements in the programs when making recommendations, including parent involvement, intensity, a predictable environment, incorporating the child's interests, actively engaging the child, and focusing on individualized developmental goals. It is important that professionals and parents are informed about the progress they can expect for their child, as well as remain aware that most research does not support a "cure" or "recovery" from autism. At this point, most of the programs focus on children of preschool age, and there is still much to learn about intervention for the birth to 3 age group.

\section{REFERENCES}

American Psychiatric Association. (1994). Diagnostic and statistical manual of mental disorders (4th ed.) Washington, DC: Author.

Bartak, L., \& Rutter, M. (1973). Special educational treatment of autistic children: A comparative study: I. Design of study and characteristics of units. Journal of Child Psychology and Psychiatry and Allied Disciplines, 14(3), 161-179.

Buffington, D. M., Krantz, P. J., McClannahan, L. E., \& Poulson, C. L. (1998). Procedures for teaching appropriate gestural communication skills to children with autism. Journal of Autism and Developmental Disorders, 28(6), 535-545.

Chakrabarti, S., \& Fombonne, E. (2001). Pervasive developmental disorders in preschool children. JAMA, Special Issue, 285(24), 3093-3099.

Charlop, M. H., Schreibman, L., \& Thibodeau, M. G. (1985). Increasing spontaneous verbal responding in autistic children using a time delay procedure. Journal of Applied Behavior Analysis, 18(2), 155-166.

Charlop, M. H., \& Trasowech, J. E. (1991). Increasing autistic children's daily spontaneous speech. Journal of Applied Behavior Analysis, 24(4), 747-761.

Cheadle, J. P., Gill, H., Fleming, N., Maynard, J., Kerr, A., Leonard, H., et al. (2000). Long-read sequence analysis of the MECP2 gene in Rett syndrome patients: Correlation of disease severity with mutation type and location. Human Molecular Genetics, 9(7), 11191129.

Cox, A., Klein, K., Charman, T., Baird, G., Baron-Cohen, S., Swettenham, J., et al. (1999). Autism spectrum disorders at 20 and 42 months of age: Stability of clinical and ADI-R diagnosis. Journal of Child Psychology and Psychiatry and Allied Disciplines, 40(5), 719-732.
Dawson, G., \& Osterling, J. (1997). Early intervention in autism. In M. J. Guralnick (Ed.), The effectiveness of early intervention (pp. 307-326). Baltimore: Brookes.

Filipek, P. A., Accardo, P. J., Ashwal, S., Baranek, G. T., Cook, E. H., Jr., Dawson, G., et al. (2000). Practice parameter: Screening and diagnosis of autism: Report of the Quality Standards Subcommittee of the American Academy of Neurology and the Child Neurology Society. Neurology, 55(4), 468-479.

Fombonne, E. (2002). Epidemiological trends in rates of autism. Molecular Psychiatry, 7(Suppl. 2), S4-S6.

Gabriels, R. L., Hill, D. E., Pierce, R. A., Rogers, S. J., \& Wehner, B. (2001). Predictors of treatment outcome in young children with autism: A retrospective study. Autism, 5(4), 407-429.

Goldstein, H. (1999). Communication intervention for children with autism: A review of treatment efficacy. Paper presented at the First Workshop of the Committee on Educational Interventions for Children with Autism, National Research Council, Department of Communication Sciences, Florida State University; December 13-14, 1999; Tallahassee, FL.

Goldstein, H., Kaczmarek, L., Pennington, R., \& Shafer, K. (1992). Peer-mediated intervention: Attending to, commenting on, and acknowledging the behavior of preschoolers with autism. Journal of Applied Behavior Analysis, 25(2), 289-305.

Greenspan, S., \& Wieder, S. (1997). Developmental patterns and outcomes in infants and children with disorders in relating and communicating: A chart review of 200 cases of children with autism spectrum diagnoses. Journal of Developmental and Learning Disorders, 1(1), 87-141. 
Harris, S. L., \& Handleman, J. S. (2000). Age and IQ at intake as predictors of placement for young children with autism: A four- to six-year follow-up. Journal of Autism and Developmental Disorders, 30(2), 137142.

Harris, S. L., \& Handleman, J. S. (Eds.). (1994). Preschool education programs for children with autism. Austin, TX: Pro-Ed.

Harris, S. L., \& Weiss, M. J. (1998). Right from the start: Behavioral intervention for young children with autism. Bethesda, MD: Woodbine House.

Hart, B. (1985). Naturalistic language training strategies. In S. F. Warren \& A. Rogers-Warren (Eds.), Teaching functional language (pp. 63-88). Baltimore: University Park Press.

Horner, R. H., Carr, E. G., Strain, P. S., Todd, A. W., \& Reed, H. K. (2000). Problem behavior interventions for young children with autism: A research synthesis. Paper presented at the Second Workshop of the Committee on Educational Interventions for Children with Autism, National Research Council, Department of Special Education, University of Oregon; April 12, 2000; Eugene, OR.

Horner, R. H., Dunlap, G., Koegel, R. L., Carr, E. G., Sailor, W., Anderson, J. A., et al. (1990). Toward a technology of "nonaversive" behavioral support. Journal of the Association for Persons With Severe Handicaps, 15(3), 125-132.

Hoyson, M., Jamison, B., \& Strain, P. S. (1984). Individualized group instruction of normally developing and autistic-like children: The LEAP curriculum model. Journal of the Division for Early Childhood, 8, 157172.

Hwang, B., \& Hughes, C. (2000). Increasing early socialcommunicative skills of preverbal preschool children with autism through social interactive training. Jour nal of the Association for Persons With Severe Handicaps, 25(1), 18-28.

Kaiser, A. (1993). Functional language. In M. Snell (Ed.), Instruction of students with severe disabilities (pp. 347-379). New York: Macmillan Publishing Co.

Kaiser, A. P., Yoder, P. J., \& Keetz, A. (1992). Evaluating milieu teaching. In S. F. Warren \& J. Reichle (Eds.), Causes and effects in communication and language intervention (Vol. 1 ed., pp. 9-47). Baltimore: Paul H. Brookes.

Koegel, L. K. (1995). Communication and language intervention. In Teaching children with autism: Strategies for initiating positive interactions and improving learning opportunities (pp. 17-32). Baltimore: Paul H. Brookes.

Koegel, R. L., Camarata, S., Koegel, L. K., Ben-Tall, A., \& Smith, A. E. (1998). Increasing speech intelligibility in children with autism. Journal of Autism and Developmental Disorders, 28(3), 241-251.

Koegel, R. L., Koegel, L. K., \& Surratt, A. (1992). Language intervention and disruptive behavior in preschool chil- dren with autism. Journal of Autism and Developmental Disorders, 22(2), 141-153.

Koegel, R. L., O'Dell, M. C., \& Koegel, L. K. (1987). A natural language teaching paradigm for nonverbal autistic children. Journal of Autism and Developmental Disorders, 17(2), 187-200.

Krantz, P. J., Zalewski, S., Hall, L., Fenski, E., \& McClannahan, L. E. (1981). Teaching complex language to autistic children. Analysis \& Intervention in Developmental Disabilities, 1(3, Suppl. 4), 259-297.

Lewy, A. L., \& Dawson, G. (1992). Social stimulation and joint attention in young autistic children. Journal of Abnormal Child Psychology, 20(6), 555-566.

Lord, C. (1995). Follow-up of two-year-olds referred for possible autism. Journal of Child Psychology and Psychiatry and Allied Disciplines, 36(8), 13651382.

Lord, C., \& McGee, J. P. (2001). Educating children with autism. Washington, DC: National Academy Press.

Lord, C., \& Risi, S. (1998). Frameworks and methods in diagnosing autism spectrum disorders. Mental Retardation and Developmental Disabilities Research Reviews: Special Issue: Autism, 4(2), 90-96.

Lord, C., \& Schopler, E. (1989). The role of age at assessment, developmental level, and test in the stability of intelligence scores in young autistic children. Journal of Autism and Developmental Disorders, 19(4), 483499.

Lovaas, O. I. (1987). Behavioral treatment and normal educational and intellectual functioning in young autistic children. Journal of Consulting and Clinical Psychology, 55(1), 3-9.

Luiselli, J. K, Cannon, B. O., Ellis, J. T., Sisson, R. W. (2000). Home-based behavioral interventions for young children with autism/pervasive developmental disorder: A preliminary evaluation of outcome in relation to child age and intensity of service delivery. Autism, 4(4), 389-398.

Marcus, L. M., Lansing, M., Andrews, C. E., \& Schopler, E. (1978). Improvement of teaching effectiveness in parents of autistic children. Journal of the American Academy of Child Psychiatry, 17(4), 625-639.

Maurice, C. (1993). Let me bear your voice: A family's triumph over autism. New York: Kopf.

McEachin, J. J., Smith, T., \& Lovaas, O. I. (1993). Long-term outcome for children with autism who received early intensive behavioral treatment. American Journal on Mental Retardation, 97(4), 359-372.

McGee, G. G., Krantz, P. J., \& McClannahan, L. E. (1985). The facilitative effects of incidental teaching on preposition use by autistic children. Journal of Applied Behavior Analysis, 18(1), 17-31.

McGee, G. G., Morrier, M. J., \& Daly, T. (1999). An incidental teaching approach to early intervention for toddlers with autism. Journal of the Association for Persons With Severe Handicaps, 24(3), 133-146.

McGee, G. G., Morrier, M. J., \& Daly, T. (2001). The Walden Early Childhood Programs. In J. Handleman \& S. L. 
Harris (Eds.). Preschool education programs for children with autism (2nd ed., pp. 157-190). Autism: Pro-ed.

Mesibov, G. B. (1997). Formal and informal measures on the effectiveness of the TEACCH program. Autism, 1(1), 25-35.

Miller, J. N., \& Ozonoff, S. (1997). Did Asperger's cases have Asperger disorder? A research note. Journal of Child Psychology and Psychiatry and Allied Disciplines, 38(2), 247-251.

Ozonoff, S., \& Cathcart, K. (1998). Effectiveness of a home program intervention for young children with autism. Journal of Autism and Developmental Disorders, 28(1), 25-32.

Panerai, S., Ferrante, L., \& Zingale, M. (2002). Benefits of the Treatment and Education of Autistic and Communication Handicapped Children (TEACCH) programme as compared with a non-specific approach. Journal of Intellectual Disability Research, 46(4), 318-327.

Pierce, K., \& Schreibman, L. (1995). Increasing complex social behaviors in children with autism: Effects of peer-implemented pivotal response training. Journal of Applied Behavior Analysis, 28(3), 285-295.

Rogers, S. J., \& Lewis, H. (1989). An effective day treatment model for young children with pervasive developmental disorders. Journal of the American Academy of Child and Adolescent Psychiatry, 28(2), 207-214.

Schopler, E., Mesibov, G., \& Baker, A. (1982). Evaluation of treatment for autistic children and their parents. Journal of the American Academy of Child Psychiatry, 21(3), 262-267.

Sheinkopf, S. J., \& Siegel, B. (1998). Home based behavioral treatment of young children with autism. Journal of Autism and Developmental Disorders, 28(1), 1523.

Smith, T., Groen, A. D., \& Wynn, J. W. (2000). Randomized trial of intensive early intervention for children with pervasive developmental disorder. American Journal on Mental Retardation, 105(4), 269-285.
Stahmer, A. C. (1995). Teaching symbolic play skills to children with autism using pivotal response training. Journal of Autism and Developmental Disorders, 25(2), 123-141.

Stone, W. L., Lee, E. B., Ashford, L., Brissie, J., Hepburn, S. L., Coonrod, E. E., et al. (1999). Can autism be diagnosed accurately in children under 3 years? Journal of Child Psychology and Psychiatry and Allied Disciplines, 40(2), 219-226.

Strain, P. S., Kerr, M. M., \& Ragland, E. U. (1979). Effects of peer-mediated social initiations and prompting/reinforcement procedures on the social behavior of autistic children. Journal of Autism and Developmental Disorders, 9(1), 41-54.

Strain, P. S., Shores, R. E., \& Timm, M. A. (1977). Effects of peer social initiations on the behavior of withdrawn preschool children. Journal of Applied Behavior Analysis, 10(2), 289-298.

Thorp, D. M., Stahmer, A. C., \& Schreibman, L. (1995). Effects of sociodramatic play training on children with autism. Journal of Autism and Developmental Disorders, 25(3), 265-282.

Towbin, K. E. (1997). Pervasive developmental disorder not otherwise specified. In D. J. Cohen \& F. R. Volkmar (Eds.), The handbook of autism and other pervasive developmental disorders (2nd ed., pp. 123-147). New York: Wiley.

Watson, L. R., Lord, C., Schaffer, B., \& Schopler, E. (1989). Teaching spontaneous communication to autistic and developmentally handicapped children. New York: Irvington Publishers Inc.

Wetherby, A. M., \& Prizant, B. M. (1999). Enhancing language and communication development in autism: Assessment and intervention guidelines. In D. B. Zager (Ed.), Autism: Identification, education, and treatment (2nd ed., pp. 141-174). Mahwah, NJ: Erlbaum.

World Health Organization. (1992). The ICD 10 Classification of Mental and Behavioral Disorders: Clinical Descriptions and Diagnostic Guidelines. Geneva, Switzerland: World Health Organization.

\title{
Current articles: http://depts.washington.edu/isei/iyc/iyc_comments.html
}

\author{
Back to list of previous articles: \\ http://depts.washington.edu/isei/iyc/iyc_previous.html
}

